\title{
O simbolismo cromático da cor preta no design das capas de discos da Tropicália
}

\section{The chromatic symbolism of black color in the design of Tropicália's disc covers}

\author{
Cláudio de Sousa Teixeira ${ }^{[1]}$, \\ Maycon Gustavo Costa dos Anjos ${ }^{[2]}$
}

\begin{abstract}
Resumo: Este artigo tem como objetivo analisar o uso simbólico do preto e seu discurso representativo através das capas de discos da Tropicália, produzida no ano de 1968, no Brasil. Partindo do pressuposto de que a década de 1960, em termos cromáticos, não se caracterizou apenas pela influência da profusão de cores impulsionada pela eclosão dos movimentos psicodélicos e da Pop Art nos EUA. Percebe-se então o uso do preto sob uma nova inflexão simbólica através de movimentos alternativos (artísticos e culturais) durante o século XX. De tal modo, essa função que se impôs como uma representação identitária constatada no invólucro desses álbuns (aqui observados através da análise semiótica) e amparada por uma pesquisa bibliográfica e documental, não se encontra apenas no campo do elegante e do moderno, mas sim como simbolismo de negação, tendo em vista os signos apresentados e reverenciados por um sentido diferente do que era utilizado em outras épocas, ao mesmo tempo em que se apresentava como oposição perante as cores nacionais utilizadas. O design gráfico tropicalista, em 1968, provocou um impacto visual subjetivamente reflexivo e conceitual, proporcionado por um hibridismo semiótico que reflete um movimento estético, principalmente através de suas cores, elementos de grande ênfase em suas capas. Contudo, percebe-se que não só o fenômeno percebido como profusão de cores merece atenção por parte da comunidade científica, mas também a função
\end{abstract}

[1] Mestre em Design, UFCG. claudio.sout@gmail.com

[2] Mestre em Design, UFCG. maycongustavo7@gmail.com 
do preto, a qual esta pesquisa se dedica, a fim de entender o simbolismo e a influência cultural das convenções sociais perante o uso da cor.

Palavras-chave: Design. Cores. Semiótica. Tropicália. Capas de discos.

Abstract: This article aims to analyze the symbolic use of black and its representative speech through the Tropicalia album covers, produced in 1968, in Brazil. Assuming that the 1960s in chromatic terms, not characterized only by the influence of the profusion of colors driven by the outbreak of the psychedelic movement and Pop Art in the USA. The use of black is then perceived under a new symbolic inflection through alternative movements (artistic and cultural) during the twentieth century. So, this function that has established itself as an identity representation found in the shell of these albums (here observed through semiotic analysis) and supported by a literature and documentary, not only is in the elegant and modern field, but as denial of symbolism, in view of the presented signs and revered by a different direction than was used at other times, while it appeared as opposition in the national colors used. The Tropicalia graphic design in 1968, caused a subjectively reflective and conceptual visual impact, provided by a semiotic hybridity reflecting an aesthetic movement, mainly through its colors, large elements of emphasis on their covers. However, it is clear that not only the phenomenon perceived as riot of color deserves attention from the scientific community, but also the function of the black, which this research is dedicated in order to understand the symbolism and cultural influence of social conventions before the use of color.

Keywords: Design. Colors. Semiotics. Tropicália. Album covers.

\section{INTRODUÇÃO}

Como importante manifestação cultural, o design constrói significados e difunde mensagens a partir do conjunto de elementos visuais que configuram produtos e artefatos. Nesse processo, em meio aos outros elementos, a cor torna-se relevante para se atingir os objetivos de comunicação, e pode-se analisar a sua influência considerando a cultura e as convenções sociais criadas pela sociedade (TEIXERA, 2018).

Para compreender o uso das cores em suas instâncias mais profundas, é necessário considerar primeiramente que a sociedade, ao longo dos tempos, costuma adotar valores representativos que acompanham o seu desenvolvimento social e cultural (PEDROSA, 2014). Pode-se então afirmar, que o simbolismo cromático na cultura é fruto de um condicionamento nascido através de símbolos criados pela sociedade.

Diante dessa dinâmica, a Tropicália, movimento estético e abrangente surgido no Brasil no ano de 1967, teve como ápice de sua produção artística e cultural (em especial, na 
música) o ano de 1968. Ano esse em que diversos jovens do mundo inteiro foram muito atuantes na sociedade, tanto na política, atuando em movimentos de protestos, quanto na produção cultural que expressava sua crítica ao conformismo estabelecido (ZAPPA;SOTO, 2011).

No Brasil, no campo do design das capas de discos ( $L P$ 's - Long Plays) tropicalistas, essa crítica se expressa por meio de uma ruptura dos padrões gráficos por meio do experimental, conduzindo conceitos que validaram um prenúncio do que seria considerado um design pós-moderno (RODRIGUES, 2007).

De acordo com Teixeira (2018), as características gráficas dessas capas de discos expressam inovação por meio do experimentalismo, numa abordagem que aproxima arte e design, entre outras características, pelo uso de mensagens presentes nas cores, que ampararam o caráter crítico e ideológico de movimentos da contracultura.

Nesse cenário, sua estética reflete o contexto cultural da época. Uma das características do design tropicalista é a profusão de cores (ibid.). No entanto, observa-se que a cor preta é também recorrente nesses invólucros, de onde se infere sua importância na construção da estética do movimento e na construção de significados que remetem ao rompimento de cânones sociais.

Weaver (2015, p. 4, tradução nossa) explica o simbolismo cromático como sendo "o uso da cor para descrever ou representar algum significado particular da sociedade ou cultura". Seu pensamento corrobora com o pensamento de Pastoreau (2008), o qual defende que a cultura vivenciada pela sociedade faz da cor um elemento de representação social, construindo assim códigos culturais e valores próprios.

Portanto, a presente pesquisa tem como objetivo geral analisar o simbolismo cromático da cor preta presente no plano de discurso das capas de discos da Tropicália produzidos no ano de 1968. Tendo como base fundamental a contextualização histórica do uso da cor preta ligada às metodologias de análise de imagem. 


\section{COR E CULTURA}

Os conceitos de liberdade e contestação na cultura, atitudes enfatizadas na rebeldia jovem dos anos 1950/60 são objetos de estudos de diversos autores, a exemplo de Caldas (2008) e Carmo (2003). Para Pastoreau (2011), o preto pode mostrar-se rebelde ou transgressor, típico da revolta. Segundo o autor, na segunda metade do século $X X$, essa revolta passou a ser expressa pelas roupas pretas, como pode ser observado durante os protestos de maio de 1968, em Paris, na França (Ver Figura 1).

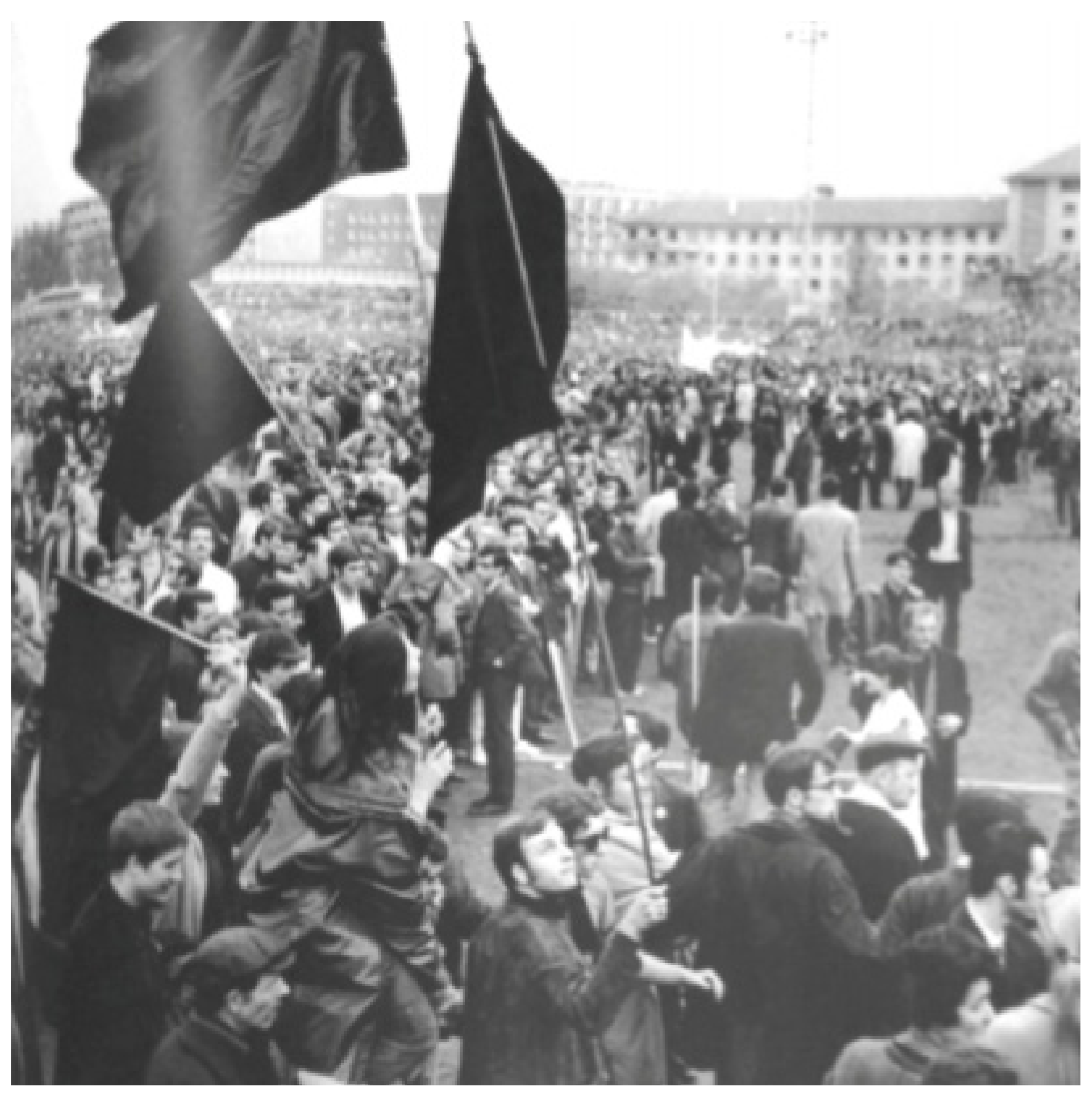

Figura 1: Encontro de estudantes no estádio Charléty, em Paris, 27 de maio de 1968. Fonte: reprodução/Pastoreau (2011). 
Nascida durante a Revolução Francesa, a bandeira vermelha acompanha as insurreições populares e as revoltas operárias ao longo do século XIX. A partir dos anos 18801900 , é pouco a pouco ultrapassada na ala esquerdista pela bandeira preta, emblema dos movimentos anarquistas e símbolo do desespero (PASTOREAU, 2008, p. 188).

Nesse contexto, percebemos a recorrência do uso de signos como forma de expressão, sobretudo os signos cromáticos que, atrelados à forma e ao contexto alternativo em que os jovens se inserem, simbolicamente proporcionam identidades culturais.

A cor possui um papel fundamental no que se refere à construção dessas identidades ao desempenhar funções que vão além de uma simples expressão, uma vez que envolve também outras áreas do conhecimento. Weaver (2014) explica que o simbolismo da cor vem sendo utilizado por séculos, embora não seja estável, mudando de cultura para cultura e até mesmo com o passar dos tempos. Contudo, Weaver (ibid., p. 05 , tradução livre) trata o conceito de simbolismo como sendo o "uso da cor para descrever ou representar algo em particular relacionado à sociedade ou cultura".

Com as mudanças da sociedade e o surgimento de novos significados, as cores possuem um papel fundamental como representações dos seus anseios, consequência também de suas necessidades, ou seja, decorrência do condicionamento em que se vive. Em meio a essa construção de significados, a juventude passa a ter novos gostos, que não o mainstream, ou seja, que não o gosto popular.

Rodrigues (2007, p. 16) explica que "é durante os anos 1960/70 que o design gráfico correspondeu às necessidades de uma cultura jovem que se estabelecia como público consumidor desde os anos 1950", o que se inclui também o desejo estético, principalmente relacionado à cor, um dos elementos plásticos mais atrativos em termos visuais. Então o que se percebe são novas mudanças no modo de se perceber a cor com o passar dos tempos, o que corrobora com o pensamento de Pedrosa (2014, p. 110) ao explicar que 
historicamente muitos dos significados das cores guardam o sentido original enriquecidos com a evolução dos povos. A cada nova sociedade, os símbolos tornam-se mais requintados e abstratos, acompanhando de perto o voo da fantasia e das aspirações humanas.

A interpretação semiótica desses fenômenos, expressos a partir de determinados contextos, pode servir como uma busca por uma percepção mais profunda, a fim de compreender o condicionamento sociocultural como origem de códigos cromáticos. A moda, a música, o design, entre outras expressões artísticas e culturais, inclusive a própria publicidade na mídia, lançam a cor em um contexto extremamente importante perante a sociedade, embora nem sempre dando seu real valor simbólico. Como por exemplo, quando utilizada como cosmética (como adorno supérfluo), desprezando o seu sentido e representação (BATCHELOR, 2007).

Em alguns momentos da história como, por exemplo, o uso do sóbrio (ausência de cores) não surpreendia tamanha sua normalidade. O excesso ou a utilização de cores mais vivas era visto como impactante. Ou seja, a audácia do uso das cores, por si só, já se manifestava como uma forma de revolução e de subversão dos cânones.

Tendo em vista as novas funções incorporadas pela cor em tempos contemporâneos, Flusser (2008, p. 127) esclarece que:

[...] nos concentrar num aspecto isolado dessa revolução - a saber, nos códigos - com a esperança de que isso seja suficiente para transmitir a radicalidade da presente renovação. Se compararmos nossa situação atual com aquela que existia pouco antes da Segunda Guerra Mundial, ficaremos impressionados com a relativa ausência de cores no período anterior à guerra. A arquitetura e o maquinário, os livros e as ferramentas, as roupas e os alimentos eram predominantemente cinzentos. [...] somos programados por cores, que são um aspecto do mundo codificado em que vivemos.

Para o autor, essas mudanças atuais, não são apenas fenômenos estéticos em termos sensíveis, passando também 
a ter sentido em termos simbólicos (cognoscíveis - passível de ser reconhecido), ou seja, no plano de expressão e no plano de conteúdo respectivamente. Seu pensamento defende uma maior importância diante do significado, não só perante a cor, mas também diante do mundo que é codificado por ela.

Contudo, antes de se debruçar sobre esse assunto, impera-se aqui a necessidade de contextualizar historicamente o uso da cor preta afim de melhor entender o seu uso na contemporaneidade.

\section{UM BREVE CONTEXTO HISTÓRICO DA COR PRETA}

A partir dos estudos históricos de Pastoreau (2008), percebemos que desde os tempos mais remotos, no Ocidente, o preto já era visto como uma cor negativa e ameaçadora, o que também não o impediu de ser convencionado posteriormente também por meio de uma visão menos negativa e até mesmo positiva, assumindo escopos diferentes com o passar dos tempos.

Por volta do ano 1000 d.C., essa cor passou a se tornar mais presente na vida cotidiana das pessoas, estabelecendo códigos sociais diferentes, com a presença de um preto "bom" (sendo associada à humildade, à moderação, à autoridade ou dignidade) e um preto "mau", possuindo certa tendência a representar o que era negativo:

Os discursos dos teólogos e moralistas, as práticas litúrgicas e funerárias, a criação artística e a iconografias, os costumes cavalheirescos e os primeiros códigos da heráldica, tudo concorre para fazer do preto uma cor sinistra e mortífera. (PASTOREAU, 2008, p. 44)

Todavia, a partir do final do século XIII até a metade do século XVII, (antecedendo a idade moderna), ela tende a perder o status negativo, associando-se ao luxo, como por exemplo, no uso pela realeza (príncipes). Entretanto, ainda com "tendência" a ser vista como uma cor "negativa" perante a sociedade, principalmente em alguns contextos, como por 
exemplo, quando atrelada às atividades ligadas à feitiçaria ou mesmo nas práticas do luto. Este último, como oposição "nascimento" versus "felicidade" (morte versus tristeza).

No campo técnico-científico, mais precisamente no ano 1666, o preto adquire o status de "não cor" ou uma cor "não verdadeira", em virtude das experiências realizadas por Isaac Newton, através do Prisma, quando ele verifica a decomposição da luz branca em seu spectro. Visto que, segundo tais experimentos, a soma de todas as cores do arco-íris gera a cor branca e o preto é a ausência de todas as cores, convencionando-se uma "não cor" (HELLER, 2010).

A partir desse momento, com a reforma protestante e os experimentos de Newton (Figura 2), sob uma nova ordem, separava-se o preto e branco de um lado e as cores do outro (sobriedade $x$ profusão).

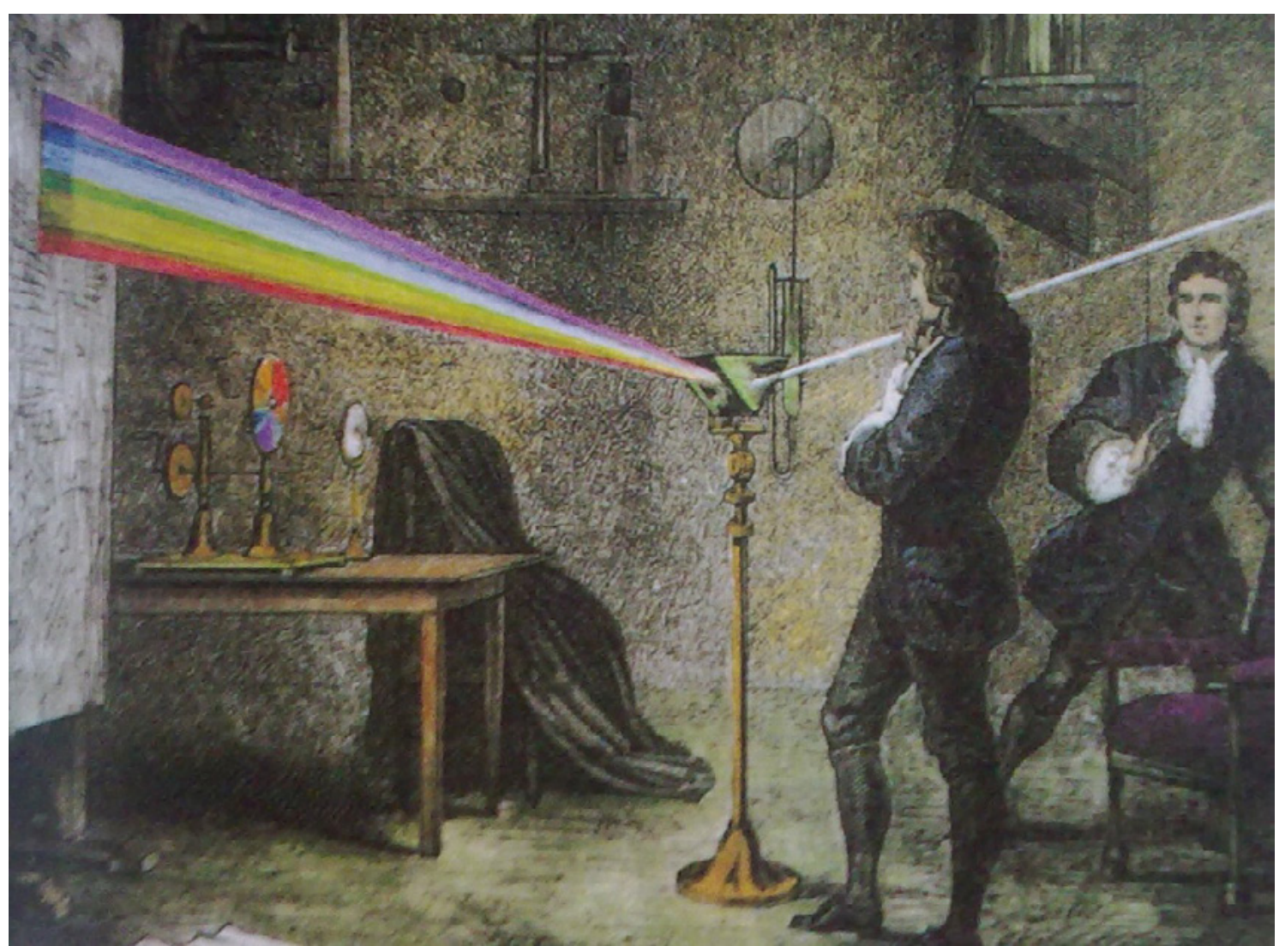

Figura 2: Ilustração da experiência de Newton $(1642-1727)$. Fonte: http://rededosaberfisico.xpg.uol. com.br/sistemas_dispersao.htm 
No final do século XIX, o preto desconsiderado pelo campo científico (tido como não-cor), com a Reforma Protestante, traz uma conotação de austeridade sóbria, em oposição ao uso das cores. Todavia, utilizada com simbolismo de humildade e simplicidade, além de moralidade. Em termo simbólico e considerado até então como uma "não cor", começa então a se introduzir o status que o preto tinha antes: o de cor verdadeira, consolidando-se no início do século XX.

Pastoreau (2008) explica que por volta de 1910, os artistas plásticos foram uns dos primeiros a resgatar essa ideia de que o preto era uma cor verdadeira, mas a maior ênfase se deu em outros campos, a exemplo da moda e do design. Ou seja, o preto como cor autêntica se consolida novamente, exaltando também a sua importância em termos simbólicos.

Todavia, embora os pintores tenham sido os primeiros a devolver ao preto sua plena modernidade, desde antes da Primeira Guerra Mundial e ao longo de todo o século foram sobretudo designers, estilistas e costureiros que asseguraram sua presença na moda, no universo social e na vida cotidiana. O preto do design não é nem o preto principesco e luxuoso dos séculos precedentes, nem o preto sujo e miserável das grandes cidades industriais; é um preto ao mesmo tempo sóbrio e refinado, elegante e funcional, alegre e luminoso (PASTOREAU, 2008, p. 187)

Ainda sobre o aspecto simbólico dessa cor, é importante ressaltar, que há algumas correntes do conhecimento que buscavam romper com a representação do real e/ou objetiva e passar a não representação, buscando puramente a sensibilidade plástica (o sensível, no plano da expressão), como ocorre no caso das artes plásticas, por exemplo, no Supremativismo Russo, de Kasemir Malevich (Ver Figura 3), defendido pelo ensaio de autoria homônima "The non-objective world" ou "O mundo da não representação" (tradução livre), de 1915 (WANNER, 2010). 


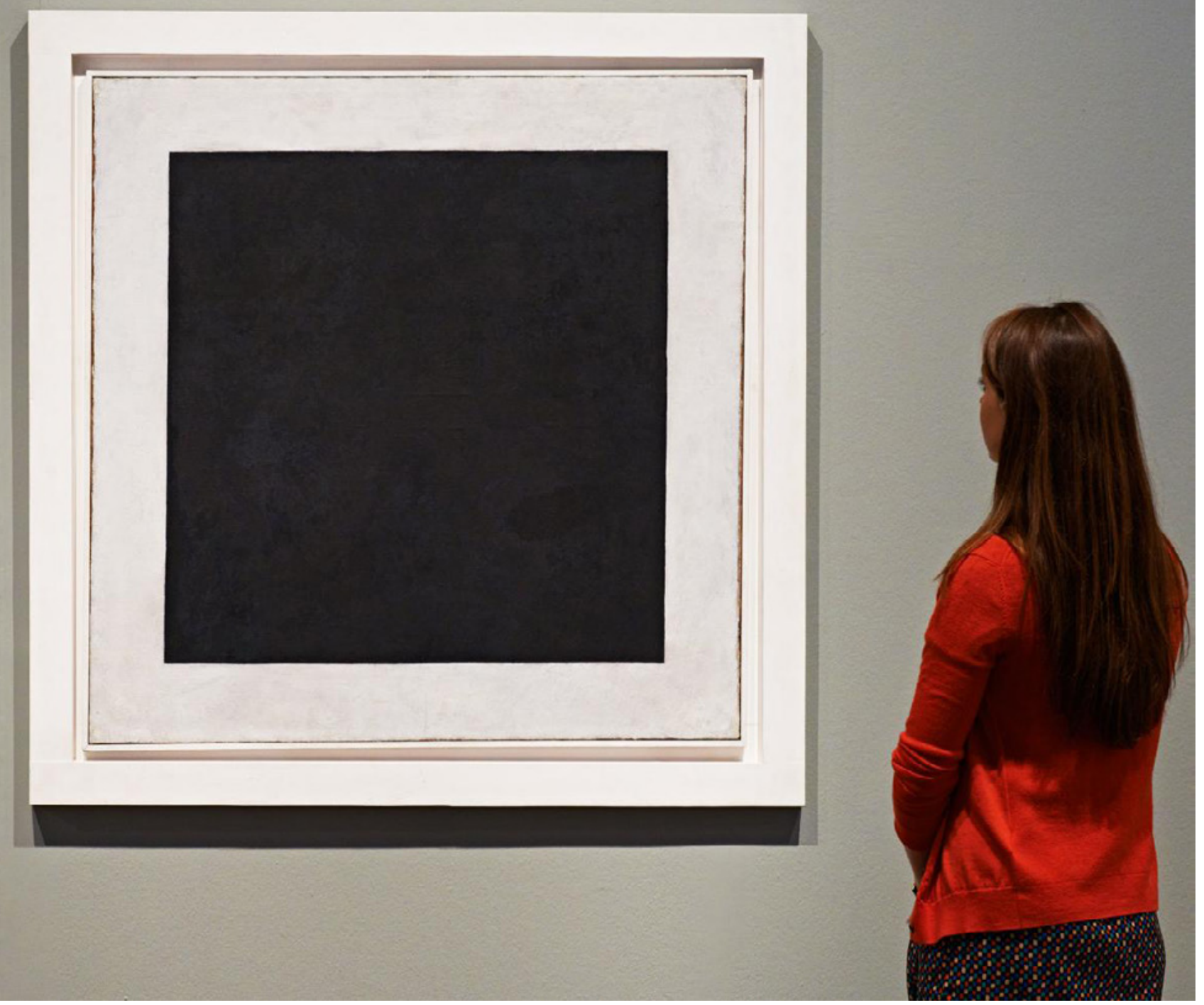

Figura 3: Kazimir Malevich Black Square (1915). Fonte: https://news. artnet.com/art-world/kizimir-

Todavia, mesmo com uso do preto como uma força conmalevich-black-square-363368 templativa de expressão perante o observador, pode gerar sensações diversas, dependendo do contexto em que ele se apresenta (considerando os signos plásticos e icônicos), pode-se se apresentar como simbólico enfatizando-se pela cor

Contudo, a capacidade de significação é demonstrada quando Wanner (ibid.) cita Santaella e Nöth (1997, p. 147) para explicar o funcionamento dessa contemplação sígnica imediatista, tal qual se apresenta a cor, no caso monocromático (preto). Segundo os autores citados por ela, pode-se negar uma "relação referencial" e ainda assim pode-se, "conforme o ponto de vista, ou não significar nada, ou se refere a 
infinitas coisas, a saber", o que demonstra ainda assim uma capacidade de "latência" em termos de significado.

Apesar de ter se consolidado "aceitável" nos dias atuais, a utilização do preto por vezes despreza a sua importância simbólica (Pastoreau, 2008) - sendo considerada meramente "cosmética", desconsiderando seu significado - não há de se negar que no século XX, algumas culturas alternativas utilizaram o preto sob novas inflexões.

Como será conceituado mais adiante, essa cor é tomada como um novo escopo através da expressão de negação, diferente do conceito usual dos séculos anteriores. Durante o século $X X$, com mais ênfase, há uma reincidência do seu uso sob uma nova função, que torna evidente também o seu caráter transgressivo utilizado em algumas esferas juvenis transviadas, que também subverte as convenções sociais. Evidentemente uma espécie de prenúncio de novas transições em campos alternativos, como bem mostra Coelho (1986, p. 43), ao explicar que o preto está inserido no campo artístico e cultural desde o final do século XIX, expresso principalmente através das vestimentas:

No mesmo momento em que Baudelaire escreve sobre o homem e o artista, na modernidade, o preto e o cinza estão se firmando como cores básicas da roupa masculina - em particular, desse mesmo artista de um demorado final de século XIX que se estende pelo século XX. O preto, acima de tudo. Na década de 50, os modernos beatniks recuperarão o preto e, mais tarde os punks escolherão novamente o preto e o cinza em suas roupas como emblema de grupo - e alimentando-se da historiografia, citando a história, serão pós-modernos. Uma existência cultural por representação, como aconteceu também com os beats existencialistas de 50: Juliette Greco canta, se veste de preto da cabeça aos pés e é amiga de intelectuais que usam o preto; uma parcela da juventude se sentirá suficientemente artista, culta, radical e contestaria se ouvir certo tipo de música e usar alguma roupa preta.

Torna-se evidente que em termos conceituais, o simbolismo cromático que o preto apresenta já não é mais o mesmo do passado. O uso dessa cor passa a se apresentar 
como uma identidade de grupos ligados à cultura juvenil, ao tempo que insere esses grupos em novos espaços rompendo com padrões pré-estabelecidos através de formas anticonvencionais, com "diferentes inflexões", como defende Harvey (2004, p. 317):

A motivação das culturas jovens é um tema a ser explorado por uma pesquisa sociológica e é com cautela que avanço a possibilidade de que o negro tenha neste mundo o valor que algumas vezes teve no passado, com diferentes inflexões, como o uniforme de um grupo que elegeu estar (ou sentir estar) fora da hierarquia de classes, mas que, ao mesmo tempo, tem a aspiração ou intenção de tornar-se uma espécie de elite.

\section{MÉTODOS E TÉCNICAS}

Para análise do simbolismo cromático da cor preta nas capas tropicalistas, utilizou-se a semiótica discursiva proposta por Joly (1996), com a finalidade de compreender o discurso apresentado. Para tanto, consideraremos a sua relação com os demais signos manifestos e latentes, que durante a análise, foram tratados sob dois eixos: Paradigmático (elementos separados - de caráter associativo) ou sintagmático (diversos elementos juntos - como um todo). Assim, para alcançarmos leituras possíveis que envolvem essas capas perante a sua natureza (imitação, traço e convenção), foram consideradas três instâncias por meio da proposta da autora supracitada: os signos plásticos (cores, formas, composição interna, textura e iluminação), signos icônicos (por seu poder analógico, ou seja, de associação como algo que se assemelha a outra coisa; figurativos) e os signos linguísticos (linguagem verbal). Este último também pode ser amparado pelo textual (por ancoragem).

Cientes de que as capas de discos tropicalistas têm como maior ênfase a profusão de cores, através de técnicas e expressões cromáticas que remetem também ao Kitsch e ao Pop (Melo, 2008), não serão desprezados tais signos (demais 
cores). Como o foco da análise é a cor (com ênfase no preto), ou seja, no âmbito dos signos plásticos, reitera-se também a necessidade de considerar também sua relação com os demais signos; principalmente os icônicos que possuem uma relação mais explícita no âmbito cultural. Nada obstante, também iremos recorrer a análises feitas por outros autores bem como contextos históricos relacionados.

A análise do simbolismo cromático da cor preta, aqui proposta, utilizou-se também da Semiótica Discursiva de Greimas, a partir de Joly (ibid.) e demais autores relacionados que amparam sua pesquisa, sob uma abordagem descritiva e qualitativa amparada por uma pesquisa bibliográfica e documental, a fim de obter as leituras possíveis perante o simbolismo cromático apresentado no discurso das capas.

\subsection{DELIMITAÇÃO DO CORPUS DA PESQUISA}

Para estabelecer o corpus de pesquisa, foi utilizado o procedimento baseado na pesquisa semiológica (Barthes, 2006), onde o corpus é abordado de forma homogênea, a fim de se obter materiais constituídos por uma única e mesma substância. No caso, foi observada a recorrência da cor em questão nas capas de discos tropicalistas produzidas durante a vigência do movimento.

Diante do componente de estudo a ser a ser analisado, o objetivo a que se pretende alcançar é compreender o simbolismo cromático do preto, sobretudo ante o plano de conteúdo. Para tanto, selecionamos seguintes capas para análise (Ver Figuras 4 a 6). 


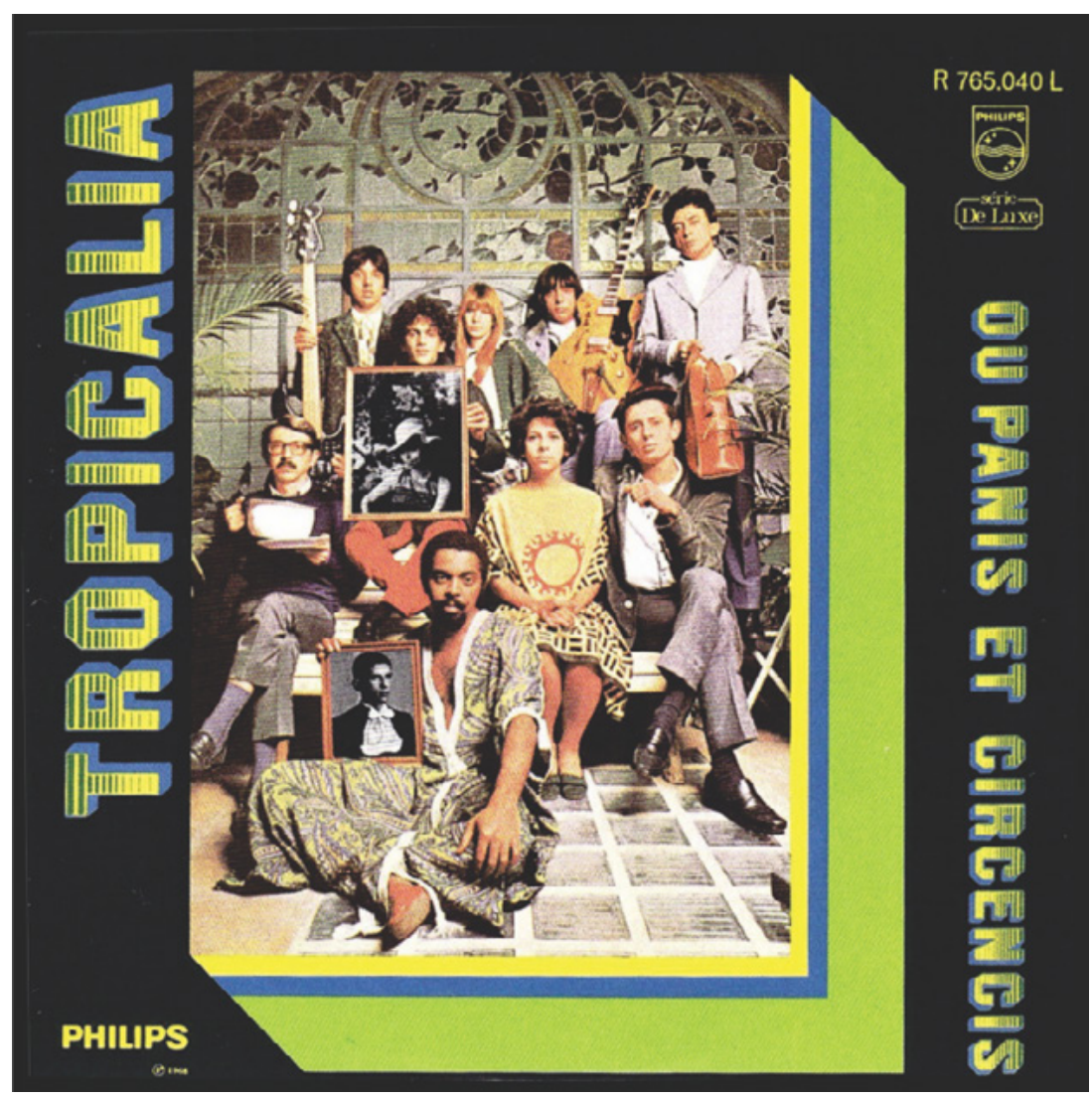

Figura 4: Tropicália ou Panis et Circencis (disco-manifesto), 1968. Fonte: Oliver Perroy.

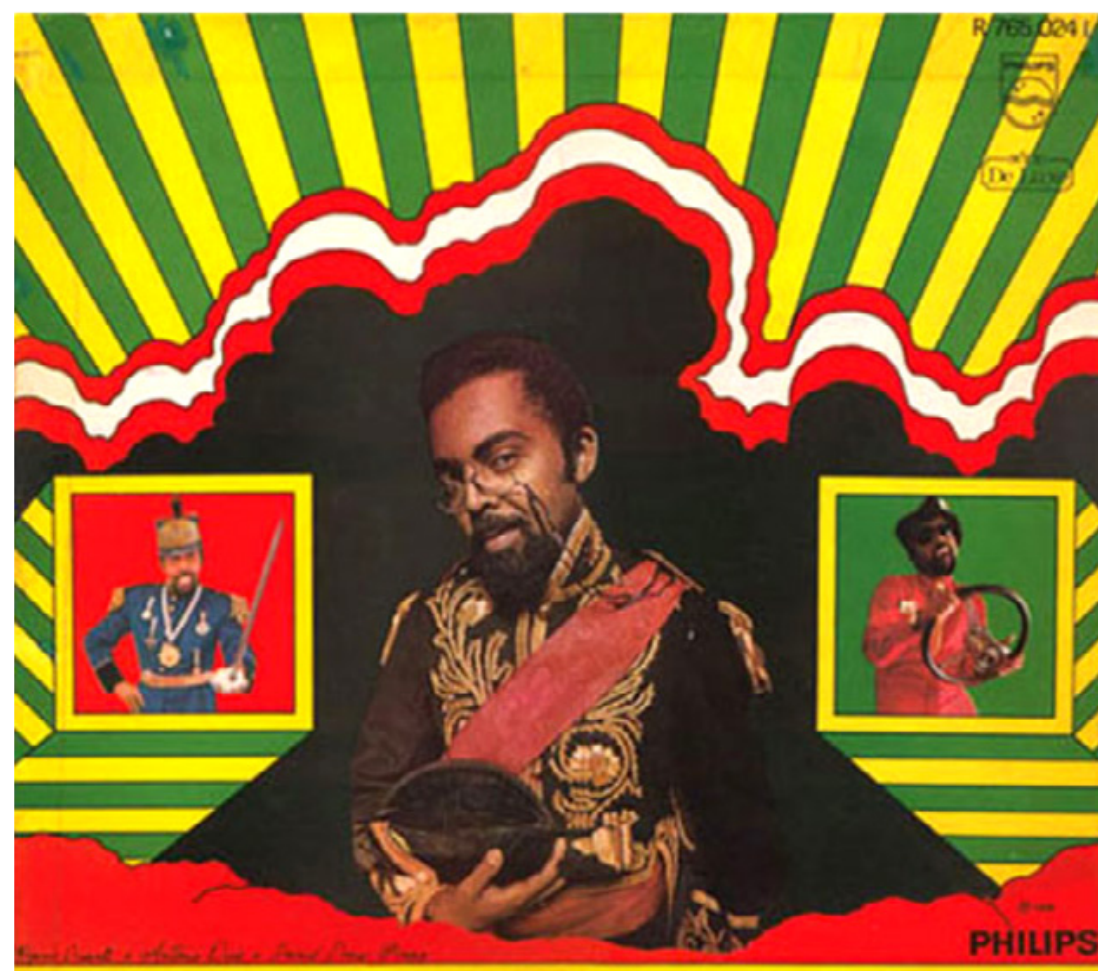

Figura 5: Gilberto Gil, 1968. Fonte: David Drew Zingg.

\section{Gifimil ime}




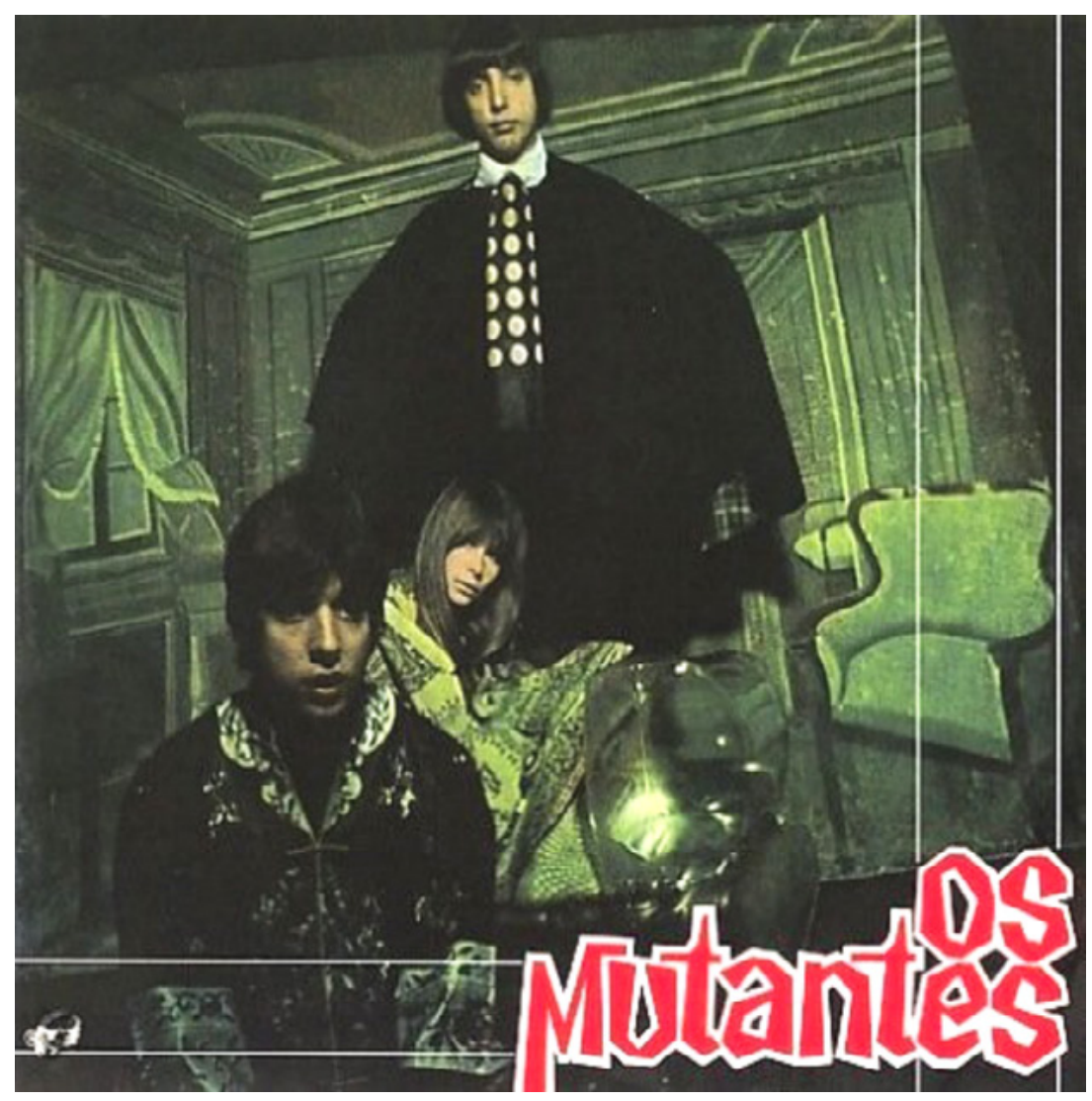

Figura 6: Os Mutantes, 1968.

Fonte: Oliver Perroy

\section{ANÁLISE E DISCUSSÃO DOS RESULTADOS}

As análises e discussões dos resultados da presente pesquisa foram apoiadas pelas evidências dos seguintes contextos de que Tropicália foi um movimento estético e abrangente, surgido no Brasil no ano de 1968, visto como contracultural, tendo em vista a influência de elementos da cultura estrangeira, e teve como sua principal representação a música (Rodrigues, 2007) em meio a áreas como as artes plásticas, o cinema, o teatro e o design. $O$ design das capas de discos em questão foram produzidos no ano de 1968, auge dos movimentos de contracultura, principalmente nos EUA e Europa, o que também influenciou o Brasil.

Em meio à ditadura militar e às transformações na esfera dos costumes, provocados por uma reação dos jovens ao conformismo (Risério, 2005), foi gerada uma maior liber- 
dade no comportamento, na moda e no design, provocando rupturas nos padrões até então utilizados. Não só o Brasil, mas vários países no mundo passavam por diversas mudanças nessa época, com maior dinâmica no âmbito da cultura juvenil, artística e intelectual. Essas mudanças resultaram em influências mescladas ao regional, experimentalismos e subjetividade (ZAPPA-SOTO, 2011), inclusive no design.

Considera-se aqui também o ponto de vista do observador (público jovem), inseridos em um contexto sócio-político e cultural, condicionado aos acontecimentos e convenções corridos no ano de 1968. Isso, de forma objetiva ou mesmo subjetiva/conceitual, faz com que, em suas esferas complexas, a trama estabelecida pelos signos também torne necessário um amparo multidisciplinar para uma análise mais concisa.

\subsection{ANÁLISE SINTÁTICA (SIGNOS PLÁSTICOS E SIGNOS ICÔNICOS)}

Com relação ao plano de conteúdo, Joly (1996, p. 113) explica que "a interpretação desses diferentes signos joga com o saber cultural e sociocultural do espectador, de cuja mente é solicitada um trabalho de associações". As associações plásticas que serão apresentadas nos quadros 01 e 02 são baseadas nas categorias de significantes e significados elencadas pela autora, além das associações já apresentadas na análise plástica, de forma mais explícita.

Foram suprimidas as análises das categorias textura e cor. A textura, tendo em vista sua não-relevância no contexto dessas capas; a cor, por ser o foco da análise, motivo que fará com que ela seja abordada na análise descritiva explicativa, após a exposição dos quadros. Justifica-se aqui esse tipo de supressão com base na autora (ibid., p. 113), ao explicar que "É claro que esse trabalho de elaboração associativa pode ser feito, assim como pode não ser feito, ou ser feito apenas parcialmente." 
Os quadros apresentam os principais significantes com seus respectivos significados relacionados às três capas, conforme citado anteriormente:

\section{Quadro 01 - Mensagem plástica e análise sintática dos signos plásticos}

\begin{tabular}{|c|c|c|c|}
\hline Significantes & Disco-manifesto & Gilberto Gil & Os Mutantes \\
\hline Iluminação & $\begin{array}{l}\text { Dura e zenital = } \\
\text { Verão, generalização }\end{array}$ & $\begin{array}{l}\text { Luz difusa = } \\
\text { Dramaticidade, } \\
\text { clausura, } \\
\text { melancolia }\end{array}$ & $\begin{array}{l}\text { Luz estroboscópica }{ }^{[3]}= \\
\text { Psicodélica, casa de show } \\
\text { / Difusa = dramaticidade, } \\
\text { clausura, melancolia }\end{array}$ \\
\hline Quadro & $\begin{array}{l}\text { Presença = } \\
\text { Concreto, racional }\end{array}$ & $\begin{array}{l}\text { Ausência = } \\
\text { Imaginário, onírico }\end{array}$ & $\begin{array}{l}\text { Ausência = } \\
\text { Imaginário, onírico }\end{array}$ \\
\hline Enquadramento & $\begin{array}{l}\text { Fechado }= \\
\text { Proximidade }\end{array}$ & Amplo = Distância & Amplo = Distância \\
\hline Composição & $\begin{array}{l}\text { Construção axial, } \\
\text { com centro focal = } \\
\text { Estabilidade }\end{array}$ & $\begin{array}{l}\text { Construção } \\
\text { ao centro = } \\
\text { Estabilidade }\end{array}$ & $\begin{array}{l}\text { Oblíqua suave } \\
\text { ascendente à direita } \\
\text { + Dinamismo }\end{array}$ \\
\hline Formas & $\begin{array}{l}\text { Massa = moleza e } \\
\text { suavidade } \\
\text { Verticais = rigidez } \\
\text { Traços e listras = } \\
\text { Fineza }\end{array}$ & $\begin{array}{l}\text { Massa = Moleza } \\
\text { e suavidade } \\
\text { Verticais = Rigidez } \\
\text { Traços e listras } \\
\text { = Fineza }\end{array}$ & $\begin{array}{l}\text { Massa = moleza e } \\
\text { suavidade }\end{array}$ \\
\hline
\end{tabular}

\section{Quadro 02 -Mensagem icônica e análise sintática dos signos icônicos}

\section{Disco-manifesto}

Gilberto Gil

\section{Os Mutantes}

Chávena-Urinol com Rogério Duprat $=$ Duchamp (Rodrigues, 2007, p. 58)

= Dadaísmo, nonsense ou

Vanguarda europeia Luz difusa = Dramaticidade,
clausura, melancolia
Luz estroboscópica = Psicodélica, casa de show / Difusa = dramaticidade, clausura, melancolia
[3] As drogas eram legais na Califórnia até 1966, e sua influência na percepção, imitada nos concertos através de luzes estroboscópicas, era simulada no trabalho gráfico por meio de uma deslumbrante repetição de contrastes cromáticos, seja entre o preto e branco, seja entre as cores complementares (HOLLIS, 2005, p. 196).
"Os Mutantes trazendo guitarras elétricas, o pop, o moderno". (ibid., p. 59) $=$ *Pop, moderno

Pose à maneira de retratos patriarcais (ibid., p. 58) = *Vanguarda / movimento articulado

\section{Militar empunhando} uma espada (ibid.) = *Deboche / crítica à ditadura, autoritarismo

Piloto, debochado, apenas com o volante (ibid.) = Deboche / Irreverência, Liberdade

\author{
Montagem junto à \\ pintura de uma sala \\ (Real vs Imaginário $)=$ \\ surreal, psicodélico \\ Roupas anticonvencionais \\ e a distorção do \\ espaço = Atmosfera \\ *anárquica e irônica
}




\subsection{VERDE-AMARELO VERSUS PRETO}

Antes de darmos início a uma análise mais profunda, falaremos sobre as cores Verde-Amarelo versus Preto, comuns às três capas selecionadas.

O plano de expressão dos signos plásticos das capas tropicalistas em questão tem como principal ênfase o uso do Verde e Amarelo em cores "sólidas", com transições abruptas entre elas. A menor ênfase se dá na capa Os Mutantes (figura 05), em que essas cores fazem transições em degradês proporcionadas por: textura, iluminação e linhas mais suaves na composição. Ainda assim, o verde e amarelo nessa capa também se faz presente.

Rodrigues (2007, p. 45) cita Hélio Oiticica (1986, p. 106) para explicar a obra homônima (Tropicália) que deu origem ao nome do movimento esclarecendo que a "Tropicália é a primeiríssima tentativa consciente, objetiva, de impor uma imagem obviamente brasileira ao contexto atual da vanguarda e das manifestações em geral da arte nacional". Ao falar em manifestações gerais da arte, o autor refere-se às manifestações do movimento em termos estéticos e conceituais. Nesse sentido, dentro de um contexto cultural, por se tratar de um movimento brasileiro, em que seu nome refere linguisticamente também ao clima tropical, infere-se que o Verde e Amarelo, culturalmente seja uma relação com as cores nacionais da bandeira, as quais representam o Brasil.

O preto, no plano de expressão e no plano de conteúdo apresentado nas capas analisadas possui uma função primordial no discurso, no que se refere à sua oposição. Pastoreau (2008, p. 10) explica a oposição como sendo uma das funções que a cor pode obter em qualquer sociedade. "(...) uma cor nunca aparece sozinha; ela não assume sentido, não "funciona" plenamente do ponto de vista social, artístico simbólico a não ser na medida que está associada ou oposta a uma ou várias outras cores."

Esse pensamento corrobora com Favaretto (1996, p. 23), em relação às capas de discos tropicalistas, no sentido de que 
"A mistura dos elementos contraditórios, enquadráveis na posição arcaico-moderno privilegia o efeito crítico que deriva da justaposição desses elementos". Considerando-se a cor como um desses elementos, adota-se um escopo em que o moderno critica um Brasil arcaico, tendo em vista que Pastoreau (1997) relaciona o preto à representação de "modernidade", além da função de elegância.

Para Heller (2013, p. 131), o preto como sendo uma cor de negação e que "sempre que o preto estiver num acorde cromático em companhia do vermelho, amarelo ou verde, uma característica negativa será visualizada nele". Por exemplo, o acorde verde em companhia do azul e amarelo representa esperança (Heller, 2013, p. 53). Seguindo seu raciocínio, com a presença do preto diante desse acorde cromático, significará descrença. Ou, no contexto em que se encontra, o acorde verde-amarelo "nacional", com adição do preto, pode ser lido como "não-nacional" ou ainda uma oposição moderna versus não-moderno, quando remete-se ao pensamento de Pastoreau (ibid.).

O preto já conceitualmente relacionado a artistas e juventude desviada dos costumes convencionais, evidentemente pode ser interpretada em tais níveis de compreensão quando relacionado à cultural e convenções sociais e sua relação com os signos que mesmo sozinhos já trazem consigo um conceito, como defende Joly (ibid.) ao citar que, para Grupo $\mathrm{Mu}$, os signos plásticos podem não ser uma continuidade dos signos icônicos. Podem ser signos que já vêm por si só dotados de significados completos, compactuando com o pensamento de Santaella e Nöth (1997) apud Wanner (2010) citado anteriormente. Por isso defende-se o início da análise através dos signos plásticos, que segundo os autores, a interpretação será essencialmente antropológica e cultural.

Embora que as cores - o que inclui iluminação e textura - também passe por uma relação plástico-icônica. Com base nessa premissa, podemos constatar que cor, como no caso do preto, pode possuir uma carga identitária, considerado o 
contexto em que ela teve ao longo dos tempos e o escopo que incorpora diante do tema.

Para que possamos chegar a uma reflexão mais ampla sobre objeto de análise, precisamos perseguir também o discurso plástico do preto com ciência do discurso semi-simbólico, que está ligado à relação entre o plano de expressão e o plano de conteúdo (Pietroforte, 2004). Semissimbólico por haver vários tipos de articulações entre eles, articulações essas que são mais amplas. Por exemplo, funcionando como cor de negação, Heller (2013, p. 31) defende que "o preto transforma todos os significados positivos de todas as cores cromáticas em seu oposto negativo. O que soa tão teórico é uma constatação elementar prática: o preto faz a diferença entre o bem e o mal, porque ele faz também a diferença entre o dia e a noite".

\subsection{ANÁLISE DA CAPA TROPICÁLIA OU PANIS ET CIRCENCIS, 1968}

Relacionando os significados e associações dos signos plásticos e icônicos, pode-se remeter a ideia de brasilidade sob o contexto em que se encontram as cores plásticas expressas no verde e amarelo, além dos próprios personagens agrupados na fotografia, que por si só, são brasileiros natos. Quando se relaciona a pose patriarcal há ideia de vanguarda, que se impõe à frente, em termos de movimento. Para Melo (2011, p. 341), "A capa do disco-manifesto Tropicália, faz referência à tradicional foto da família reunida, ao mesmo tempo que a subverte, seja pelo figurino, seja pelas atitudes."

Quanto ao simbolismo cromático, localiza-se no Quadro de Resumo das Diferentes Funções e Significados da Cor Preta na Cultura Ocidental, de Pastoreau (1997, p. 141), identificamos as funções de "Elegância e Modernidade" a premissa de que "Os artistas gostam do preto (ou do preto e branco)" ou Design, Vanguarda, etc." Percebe-se no signo icônico apresentado no quadro, O Dadaísmo, vanguarda europeia que reverencia o nonsense (sem sentido), voltando-se para o passa- 
do, como referência de um movimento do início do século XX, o que impulsiona o rompimento dos cânones, ou seja, provocando uma oposição à cultura nacional daquela época (1968).

Para Rodrigues (2007, p. 51) apud Naves (1988:11), “Esse tipo de estética mais voltada para incorporação do passado e do presente, rejeitando as formulações utópicas delineadas para o futuro, é, analisada em diversas manifestações como a arte pop, o espírito da contracultura no geral, e o que se convencionou chamar de arte "pós-moderna".

Observados os significados: concreto, racional, proximidade, fineza e rigidez, percebe-se "formas geométricas austeras e a abstração do modernismo", o que segundo (Wolf, 2011), remetem à Arte Déco, podendo sugerir como "referente" o passado, em relação à década de 1960, corroborando com Favaretto $(1996,82)$ : “Na capa representa-se o Brasil arcaico e o provinciano; emoldurados pelo antigo, os tropicalistas representam a representação".

\subsubsection{Síntese geral da Análise da capa Tropicália ou Panis et Circencis, 1968}

A capa do disco-manifesto tem no plano de conteúdo apresentado pelo discurso do preto um simbolismo cromático de vanguarda e modernidade, onde sua função é de negar um país arcaico em termos de manifestações culturais sugerindo consequentemente o moderno.

\subsection{ANÁLISE DA CAPA GILBERTO GIL, 1968}

A capa de Gilberto Gil traz, assim como as demais, um verde-amarelo representando a brasilidade. Diante disso, o preto mais uma vez irá se opor a um contexto de cores nacionais, mais uma vez subvertendo os cânones, conforme foi mostrado anteriormente. No entanto, sob um conceito mais transgressivo que o anterior, visto que para Rodrigues (2007, p. 52) "A capa do disco, que se chamava simplesmente Gilberto Gil, era puro deboche - ao estado, à cultura e à nação". 
A ausência de enquadramento nos ícones plásticos sugerem o imaginário e o onírico, relacionando-se sinergicamente com os signos icônicos do piloto, que representa o deboche (ibid), a irreverência e a liberdade; o militar, empunhando uma espada (ibid.), representando também um deboche (ibid.), possibilitando inclusive a leitura de uma crítica subjetiva à ditadura e ao autoritarismo.

O militar está configurado em um plano de fundo quadrado vermelho, enquanto o piloto, em um plano de fundo quadrado verde. As cores fazem oposição uma à outra: Guimarães (2001, p. 117) explica que o vermelho em oposição ao verde, provoca uma "binaridade assimétrica", relacionando-se uma segunda realidade com significados opostos, a exemplo de "violência e paixão ou guerra e amor, convivendo na mesma cor". O vermelho, por si só, pode denotar ainda "cor de imposição" (ibid.). Deduz-se nesse sentido que, enquanto o militar sobre o plano de fundo vermelho, é autoridade ou imposição, o piloto, pode ser lido como liberdade. Uma preposição simples do verde vs vermelho como sendo livre vs censurado ou liberado vs proibido, como aberto vs fechado, tão comum em semáforos.

A capa traz um preto bastante enfático ao centro, como plano de fundo da fotografia principal, gerando certa dramaticidade, clausura e tristeza, impulsionadas pela iluminação difusa na fotografia. O cantor se encontra com uma vestimenta que se assemelha a um fardão da Academia Brasileira de Letras (Rodrigues, 2007) com óculos de leitura, o que denota intelectualidade, a ideia de mentor ou de "poder" (Harvey, 2004).

Utilizando a técnica da ancoragem, através da semiótica, recorre-se ao textual através da contracapa do LP, para nos ampararmos pelo texto "Gilberto Gil psicografado por Rogério Duarte":

[...] Mas eles gostam de uniformes, admitiriam até a minha nudez, contanto que depois pudessem me esfolar e estender a minha pele no meio da praça como se fosse uma bandeira, um guarda-chuva contra o amor, contra os Beatles, contra os Mutantes. [...] E esta vida 
não está sopa e eu pergunto: com que roupa eu vou pro samba que você me convidou? Qual a fantasia que eles vão me pedir que eu vista para tolerar meu corpo nu? Vou andar até explodir colorido. O negro é a soma de todas as cores. A nudez é a soma de todas as roupas." (VERSO CONTRACAPA LP - GILBERTO GIL, 1968).

Não há como afirmar como a quem o texto se refere quando o mesmo diz que "eles gostam de uniformes", embora provavelmente sejam os "militares". Todavia no plano da expressão e no plano de conteúdo apresentados pelos signos, o preto possui um discurso de poder ou de autoridade e não obstante expressa um impacto muito forte na capa, corroborando com Pastoreau (2008) que afirma o preto como sendo uma cor que em diversos momentos foi utilizada como forma de proclamar revolta, rejeição pelas convenções sociais ou ódio pela autoridade. Além disso, podia funcionar contra máximas nacionalistas da publicidade do regime militar, na década de 1960: "Brasil: Ame-o ou deixe-o!" ou "Quem não vive para servir ao Brasil, não serve para viver no Brasil", através do "puro deboche - ao estado, à cultura e à nação" (Rodrigues, 2007, p. 52).

\subsubsection{Síntese geral da capa Gilberto Gil, 1968}

A capa de Gilberto Gil tem no plano de conteúdo apresentado pelo discurso do preto um simbolismo cromático de rejeição às convenções sociais ou aversão à autoridade, com a função de negar as convenções por uma maior liberdade.

\subsection{ANÁLISE DA CAPA OS MUTANTES, 1968}

Considerando a relação entre os signos plásticos e icônicos, percebe-se na capa Os Mutantes (figura 05) a presença do verde e amarelo em menor ênfase. Todavia, essas cores fazem transições em degradês proporcionadas por: textura, iluminação e linhas mais suaves e composição ao mesmo tempo dinâmica, causando um efeito estroboscópico. Na leitura dos signos plásticos, percebe-se o Real vs Imaginário, já que 
a ausência do quadro produz a sensação imaginária, onírica, com formas mais orgânicas e suaves. Rodrigues (2007, p. 62) afirma que "A capa do primeiro LP dos Mutantes reproduz a atmosfera anárquica e irônica do grupo, assim como do movimento. A foto retrata a banda tendo ao fundo um cenário de uma sala, posicionada de forma desalinhada ao eixo da capa, criando um visual entre surreal e psicodélico."

Esse ambiente desalinhado, imaginário e onírico remete ao psicodélico e ao surreal, principalmente em relação à fusão entre imagem real e onírica - ilustração (pintura) representada pela sala, numa perspectiva e profundidade desequilibrada.

Roupas anticonvencionais, principalmente a do personagem que se impõe ao alto, na composição, traz um preto com bastante ênfase na capa. Mais uma vez o preto tem a função de negação. Ou seja, de negar as convenções, contribuindo com a atmosfera anárquica e irônica já citada. Certamente uma correlação aos estados alterados de consciência provocados pelo uso de alucinógenos ligando os signos a representações fora do mundo real. Para explicar o simbolismo desse tipo de iluminação e o efeito psicodélico nesse invólucro, recorre-se aqui a Batchelor $(2007$, p. 88) que cita o poeta e escritor Aldous Huxley: para o viajante Aldous Huxley, as cores ficavam tão intensas que "pareciam prestes a saltar das prateleiras para se jogar com veemência ainda maior" na sua atenção (extraído do livro The Doors of Perception - 1994, editora Flamingo, de Londres). Citando mais uma vez Huxley, Batchelor (ibid. p. 89), complementa esclarecendo que “Em Céu e Inferno, a sequência de Portas da Percepção, Huxley aborda a questão das pedras preciosas e do lugar que elas ocupam na literatura das drogas e dos delírios. Cita o relato de uma alucinação induzida pelo peiote, em que o autor via "fragmentos de vidro colorido" e "enormes pedras preciosas", em que ambos "pareciam ter uma luz interna". Peiote trata-se de um cacto alucinógeno.

Nesse sentido, não à toa que percebemos as influências psicodélicas nas cores adotadas na década de 1960 (Hollis, 
2005), bem como sua relação mística adotada por adeptos da contracultura, ainda mais que o Batchelor (2007) explica que no livro Céu e Inferno, de Aldous Huxley, são citados vários exemplos de ilustrações ligadas à cultura hinduísta, budista e judaico-cristão que utilizam cores de forma artificial, com o reflexo reluzente de suas tonalidades, mostrando também que no caso do brilho e variações tonais do tipo estroboscópica, pode haver conotação mística, esotérica, espiritual ou de religiosidade.

Para Weaver (2014, p. 16), “o preto representa o mistério, pois proporciona proteção contra o mundo exterior criando secretismo. É a única cor que ajudam em esconder todas as nossas inseguranças e fraquezas seja física ou emocional", mostrando esse poder que causar mistério e imaginação. (Ibid., p. 16) “O preto representa o pecado, luto e em culturas ocidentais ele representa rituais do mau, monstros e demônios. É uma cor misteriosa e pode causar imaginação para vaguear fora para o desconhecido.", corroborando com o pensamento de Pastoreau (1997) que diz que existe uma corrente mais sombria, ligada a essa modernidade, que alinha o estranho, o oculto, o frenético e até o esoterismo.

\subsubsection{Síntese geral da capa Os Mutantes, 1968}

O preto expresso na capa dos Mutantes, no seu plano de conteúdo, possui em seu simbolismo cromático uma função rejeição às convenções sociais com uma clara analogia ao uso das drogas e os estados alterados de consciência, referenciando o estranho, o oculto, o frenético e o esoterismo, conforme defende Pastoreau (1997).

\section{CONSIDERAÇÕES FINAIS}

Diante desta pesquisa, pôde-se constatar que o preto representado na estética das capas de discos da Tropicália, pode trazer consigo um simbolismo de negação e rejeição às convenções da sociedade como forma de romper com pa- 
drões pré-estabelecidos, outrora também como forma de causar um "estranhamento".

Quanto ao preto, foi observado que se trata de cor recorrente no design tropicalista, sendo uma das cores predominantes em quatro das seis capas analisadas, usado, não somente para realçar os matizes, mas complementando o discurso visual.

Constatou-se também que essa cor vem sendo inserida em diversos contextos da juventude com uma nova inflexão, contida em espaços alternativos, em alguns casos, porque quanto mais jovem o indivíduo, maior a sua preferência pelo preto (HELLER, 2010). Além disso, essa cor predileta dos designers (Ibid) e dos artistas (HARVEY, 2004).

O conceito de intelectualidade também pode ser sugerido pelo preto da capa Tropicália ou Panis et Circencis, já que esta cor está em consonância com o movimento vanguardista. Na capa de Gilberto Gil, ele representa a intelectualidade e a negação das cores nacionais, ao mesmo tempo em que remete também ao momento político sombrio na época. $\mathrm{Na}$ capa de Os Mutantes, por sua vez, o preto gera uma atmosfera dramática, reforçando a distorção da proporção das figuras e remetendo ao enigmático e ao esotérico, de forma alusiva aos estados alterados de consciência.

Considerado o que foi apresentado, o estudo do simbolismo da contracultura pode auxiliar no processo de desenvolvimento de conceitos que estejam voltados para a construção de identidades, bem como a compreensão do rompimento de padrões que tornam o design gráfico mais ciente em relação à cultura e sociedade.

Vale ressaltar que a interpretação de significado feita através das análises, segundo Joly (1996, p. 45) implica também: "estudar as circunstâncias históricas de criação de uma obra para compreendê-la melhor pode ser necessário", o que torna a leitura mais eficiente.

Para a autora, qualquer imagem é representação, mas não existem regras que a constrói. Para a compreensão por 
parte do intérprete há as convenções socioculturais que interferem nessa interpretação, ou seja, a carga cultural do indivíduo e suas articulações inerentes a essa irão contribuir diretamente com o aspecto simbólico da imagem analisada. Por isso, a teoria semiótica irá permitir compreender a capacidade sígnica analisando "semelhança, traço e convenção", isto é: "ícone, índice e símbolo".

\section{REFERÊNCIAS}

BARTHES, Roland. Elementos da semiologia. (trad.)

Izidro Blikstein. 16a . ed. São Paulo: Cultrix, 2006.

BATCHELOR, David. Cromofobia. São Paulo:

Editora Senac, 2007. Trad. Marcelo Mendes.

CALDAS, Waldenyr. A cultura da juventude: de

1950 a 1970. Vol. 10. Musa Editora, 2008.

CARMO, Paulo Sérgio do. Culturas da rebeldia:

a juventude em questão. 2 Edição. São

Paulo: Editora SENAC São Paulo, 2003.

COELHO, Teixeira. Moderno pós-

moderno. L\&PM Editores Ltda., 1986.

FAVARETTO, Celso F. Tropicália: alegoria,

alegria. Ateliê editorial, 1996.

FLUSSER, Vilém. O Mundo Codificado.

São Paulo: Cosac Naify, 2008.

GUIMARÃES, Luciano. A cor como informação: a construção biofísica, linguística e cultural da simbologia das cores. São Paulo: Annablume, 2001.

HARVEY, John. Homens de Preto. Trad. Fernanda Veríssimo. São Paulo: Editora UNESP, 2003. 
HELLER, Eva, 1948-2008. A psicologia das cores: como as cores afetam a emoção e a razão. Tradução Maria Lúcia Lopes da Silva. 1. Ed. São Paulo: Gustavo Gili, 2013.

HOLLIS, Richard. Design Gráfico: Uma História Concisa / Richard Hollis; tradução. Carlos Daudt. 1. ed. São Paulo: Martins Fontes, 2005.

JOLY, Martine. Introdução à analise da imagem. 6. ed. Campinas: Papirus, 1996.

MELO, Chico Homem de. 0 design gráfico

brasileiro: anos 60; Chico Homem de Melo (Org.)

$2^{a}$. Ed. São Paulo: Cosac: Naaify, Ed. 2008.

MELO, Chico Homem de (org.) and Elaine Ramos (org.). Linha do tempo do design gráfico no Brasil. Cosac Naify, São Paulo; $1^{\text {a }}$ edição, 2011.

PASTOUREAU, Michel. Preto: história de uma cor. Trad. Léa P. Zylberlicht. São Paulo: Editora Senac São Paulo : Imprensa Oficial do Estado de São Paulo, 2008;

PASTOREAU, Michel. Dicionário das cores do nosso tempo: simbólica e Sociedade. Trad. Maria José Figueiredo. Lisboa: Editions Bonneton. Editorial Estampa (tradução), 1997.

PEDROSA, Israel. Da Cor à Cor Inexistente. 10. Ed.

3. reimpr. Rio de Janeiro: Senac Nacional, 2014.

PIETROFORTE, Antonio Vicente. Análise do texto visual: a construção da imagem. Editora Contexto, 2007.

RODRIGUES, Jorge Caê. Anos fatais: design, música e Tropicalismo. Rio de Janeiro: 2AB, 2007.

WANNER, Maria Celeste de Almeida. Paisagens sígnicas: uma reflexão sobre as artes visuais contemporâneas. SciELO-EDUFBA, 2010. 
WEAVER, Mabel. Color Symbolism: Detailed Study of

Colors and their Meaning, Amazon Media Press, 2014.

WOLF, Peter J. Design gráfico: um dicionário

visual de termos para um design global. São

Paulo: Ed. Edgar Blücher Ltda, 2011.

ZAPPA, Regina; SOTO, Ernesto. 1968: eles só

queriam mudar o mundo. Zahar, 2011. 